\title{
Survival in Out-of-hospital Rapid Sequence Intubation of Non-Traumatic
}

\section{Brain Pathologies}

Pieter Francsois Fouche, MScMed (ClinEpi). Monash University, Department of Community Emergency Health and Paramedic Practice

Paul Andrew Jennings, PhD. Monash University, Department of Community Emergency Health and Paramedic Practice

Karen Smith, PhD. Ambulance Victoria, Research and Evaluation

Malcolm Boyle, PhD. Griffith University, School of Medicine

Gabriel Blecher, MBBS, MSc. Monash Emergency Research Collaborative, Clinical Sciences at Monash Health, Monash University; Monash Medical Centre, Emergency Program, Monash Health

Jonathan Knott, MBBS, PhD. Royal Melbourne Hospital, Emergency Research

Mani Raji, MBBS. Austin Health, Department of Emergency Medicine.

Pamela Rosengarten, MBBS. Peninsula Health, Emergency Medicine

Michael Roberto Augello, MBBS. St. Vincent’s Hospital, Emergency Medicine

Stephen Bernard, MD. Ambulance Victoria, Research and Evaluation; Department of Epidemiology and Preventive Medicine, Monash University; Intensive Care Unit, Alfred Hospital

Word Count: 3381

Corresponding author: Pieter Francsois Foucheｐfouche@ambulance.nsw.gov.au 


\section{Abstract}

\section{Introduction}

Rapid sequence intubation (RSI) is not only used in traumatic brain injuries in the out-of-hospital setting, but also for non-traumatic brain pathologies (NTBP) such as brain tumours, meningitis, encephalitis, hypoxic/anoxic brain injury, stroke, arteriovenous malformations, tumours, aneurysms, brain haemorrhage, as well as brain injury due to diabetes, seizures and toxicity, metabolic conditions and alcohol and drug overdose. Previous research suggests that RSI is common in non-traumatic coma, but with an unknown prevalence of NTBP in those that receive RSI. If NTBP is common and if brain trauma RSI evidence is not valid for NTBP then a sizable proportion of NTBP receive this treatment without evidence of benefit. This study calculated the out-of-hospital NTBP prevalence in patients that had received RSI and explored factors that predicted survival.

\section{Methods}

A retrospective cohort study based on data collected from an ambulance service and seven hospitals based in Melbourne, Australia. Non-traumatic brain pathologies were defined using ICD10-AM codes for the calculation of NTBP prevalence. Logistic regression modelled out-of-hospital predictors of survival to hospital discharge after adjustment for comorbidities.

\section{Results}

The seven participating hospitals treated 2277 patients that received paramedic RSI for all illnesses and indications from 1 January 2008 to 31 December 2015, with survival data available for 1940 (85\%). Of the 1940, 1125 (58\%) patients had at least one hospital-diagnosed NTBP. Sixty-nine percent all of NTBP survived to hospital discharge, compared to $65 \%$ for traumatic intracranial injury. Strokes were the most common and had poor survival to discharge (37\%) compared to the second most common NTBP toxicity/toxic encephalopathy that had very high survival (98\%). No out-of-hospital clinical intervention or prehospital time interval predicted survival. Factors that did predict survival include Glasgow Coma Scale (GCS), duration of mechanical ventilation, age, ICU length of stay and comorbidities.

\section{Conclusions}

Non-traumatic brain pathologies are seven times more prevalent than traumatic brain injuries in patients that underwent out-of-hospital RSI in Victoria, Australia. Since the mechanisms through which RSI impacts 
mortality might differ between traumatic brain injuries and NTBP, and given that NTBP is very prevalent, it follows that the use of RSI in NTBP could be unsupported.

\section{Introduction}

Rapid sequence intubation (RSI) is a process that utilizes sedative and paralytic drugs to facilitate the placement of an endotracheal tube. Rapid sequence intubation is used in a number of emergency medical services (EMS) worldwide, including Australia, ${ }^{1}$ numerous European countries, ${ }^{2}$ South-Africa, ${ }^{3}$ and in much of the United States. ${ }^{4}$ Rapid sequence intubation in traumatic brain injuries has been the focus of research in the last two decades. In a trial in San Diego, prehospital head injured patients who underwent paramedic RSI were compared to a matched historical control group and survival outcomes compared. Mortality was increased in the RSI cohort compared with controls (33.0\% versus $24.2 \%, \mathrm{p}<0.05){ }^{5}$ However, a more recent randomized controlled trial conducted in Australia contradicted the San Diego trial. This trial suggested favourable neurological outcome at six months for paramedic RSI, compared to inhospital RSI (RR 1.28; 95\% CI 1.00-1.64; $\mathrm{P}=0.046)^{1}$.

Rapid sequence intubation is not only used in the prehospital setting for head injuries and trauma. Bernard et al from Victoria, Australia found that 49\% of all RSIs in their emergency medical service (EMS) are on patients with a non-traumatic coma such as stroke and seizures (based on paramedic diagnosis). ${ }^{6}$ Non-traumatic brain pathologies (NTBP) is defined as an acquired brain injury (either permanent or transient) that includes brain tumours, meningitis, encephalitis, hypoxic/anoxic brain injury, stroke, arteriovenous malformations, tumours, aneurysms, brain haemorrhage, as well as brain injury due to diabetes, seizures and toxicity, metabolic conditions and alcohol and drug overdose. ${ }^{7-9}$ Whilst the prevalence of RSI for non-traumatic coma has been examined, the prevalence and survival outcomes for NTBP patients receiving paramedic RSI needs quantification. It is not clear that the evidence of effectiveness of RSI in traumatic injuries applies to NTBP, since NTBP is a heterogeneous group of pathologies and differs considerably from traumatic brain injuries in their pathophysiology. ${ }^{10}$ Additionally, if NTBP is common in those that receive RSI then it is possible that no proof of benefit exist for a sizable proportion of RSI patients. Therefore, this study aims to quantify NTBP prevalence and survival as well as factors that predict mortality in a cohort of out-of-hospital RSI by EMS in Victoria, Australia.

\section{Methods}

\section{Study Design}

A retrospective cohort study of NTBP cases in Victoria, Australia.

\section{Setting}


This cohort consisted of patients that had received RSI from Mobile Intensive Care Ambulance (MICA) Paramedics in Victoria and were transported to seven Melbourne-based hospitals for the period 1 January 2008 to 31 December 2015. Victoria is Australia's second most populous state with an area of 237,629 km² and Melbourne is the capital with a population of 4.6 million persons. Victoria has a two tier EMS system with approximately 400 MICA Paramedics in addition to 3000 Advanced Life Support (ALS) Paramedics. ${ }^{6}$ MICA paramedics use RSI in patients with coma (Glasgow Coma Score $\leq 9$ ) aged $\geq 14$ years and if transport time is more than 10 minutes to the nearest emergency department, for both traumatic and non-traumatic coma. ${ }^{6}$ Rapid sequence intubation training includes 24 hours of theoretical and manikin training and 16 hours experiential training in an operating room in addition to undergraduate and postgraduate instruction on advanced airway management. MICA paramedics undertake a one-day theoretical and practical reaccreditation examination annually. RSI medications used in NTBP include intravenous fentanyl, midazolam, atropine (for bradycardia) and suxamethonium. These drugs have significant impact on physiology and includes tachycardia (atropine), respiratory depression (fentanyl, midazolam), depressed level of consciousness (midazolam) and elevated potassium levels and increased intragastric pressure (suxamethonium). ${ }^{11}$

\section{Data collection}

We collected data retrospectively from eight sites in Melbourne: Ambulance Victoria, Monash Medical Centre, Dandenong, Alfred, Royal Melbourne, Frankston, Austin and St. Vincent's hospitals. We included all cases of RSI for the period 1 January 2008 to 31 December 2015 from the Ambulance Victoria data warehouse. Included were patients with a hospital diagnosed NTBP and either aeromedical or road transport to participating Melbourne hospitals (Fig. 1). Data extracted included prehospital interventions, medications, ambulance scene and travel time intervals, paramedic diagnosis, vital signs (observations) and demographics from Ambulance Victoria and survival data from the hospitals. Hospital data included emergency department survival, demographics, and duration of mechanical ventilation and intensive care unit (ICU) length of stay.

\section{Definitions}

For the purpose of this analysis and for inclusion into the study, we defined NTBP based on the International Statistical Classification of Diseases and Related Health Problems, Tenth Revision, Australian Modification (ICD10-AM) codes from in-hospital records for an episode of care (Table S1). ICD10-AM codes for NTBP were grouped for the pathologies: haemorrhagic stroke, ischemic stroke, other types of stroke, neoplasms of brain, inflammatory brain diseases, anoxic/hypoxic brain injury, protracted seizures, toxicity and toxic encephalopathy, hydrocephalus, diabetic metabolic encephalopathy and other miscellaneous encephalopathies. ${ }^{9,10}$ Under "toxicity and toxic encephalopathy" we included all neurotoxic toxidromes that at the very least affected the functioning of the ascending reticular activating system or 
analogous structures to cause coma. ${ }^{12}$ These pathologies were classified as NTBP if the brain injury was either permanent or transient. We excluded degenerative and congenital brain diseases; birth related trauma as well as cardiac arrest not in NTBP. ICD10-AM codes S06 - (intracranial injury) define traumatic intracranial brain injuries and did not form part of the NTBP cohort. However, we calculated the survival to hospital discharge of traumatic intracranial injuries to compare with NTBP.

Placement of endotracheal tube in the trachea beyond the vocal cords was confirmed using clinical means and/or end-tidal $\mathrm{CO}_{2}$ waveform. Clinical confirmation supported by end-tidal $\mathrm{CO} 2$ waveform and defined intubation success. Duration of mechanical ventilation is the time in days on a ventilator in ICU, and ICU length of stay was the total time for each intensive care unit admission in days. The variable “prehospital time” was composed of three intervals, the response time of the emergency vehicle from time of call plus the time spent on scene plus transport to the hospital up the time of hospital arrival. The prehospital time interval served as a proxy for the time from injury until hospital interventions. We totalled the volume of crystalloid fluids (either sodium chloride or sodium lactate) as Ambulance Victoria switched from using mainly sodium lactate to sodium chloride in 2009.

\section{Outcomes and independent variables}

Out-of-hospital variables included demographic, date, scene and transport times, case description, vital signs (observations), paramedic-administered medications, dosages and clinical procedures. In-hospital variables included demographic, date, ICD10-AM codes, duration of ICU stay and mechanical ventilation status at separation from the emergency department and hospital. The primary outcome was survival to hospital discharge, derived from the separation disposition from in-hospital records. We accounted for comorbidities with a score by van Walraven (based on the Elixhauser index) derived from ICD 10-AM codes. $^{13}$

\section{Statistical analysis}

Stata version 14 (Stata Corp, College Station, Texas, USA) was used in this analysis. We calculated descriptive statistics for the outcomes variables, and used a maximum likelihood-fitted logistic regression model for predictors of survival to hospital discharge. Variables were included in the initial baseline model if they were significant at $\mathrm{p}<0.20$ by likelihood ratio test. After step-wise elimination of non-significant variables one-at-a-time, and then back-introduction, predictors only remained in the final multivariable model if they were significant at $5 \%$ level. A change in $20 \%$ of the magnitude of estimates was used to detect the presence of confounding. ${ }^{14}$ We assessed the linearity of the logits of all continuous predictors in the multivariable model, and if there was a deviation from linearity, we fitted fractional polynomials to these non-linear terms. 
We anticipated that certain variables might have a probability mass or "spike" at the zero value and such variables were modelled as a dichotomous variable plus a linear or non-linear term if appropriate. For example, survival with certain medications and clinical interventions could "spike" at zero/no dose, ${ }^{15}$ since those that had received no medications/interventions are likely to be qualitatively different than those who did receive the medications. Medication variables that take discrete values rather than being truly continuous were modelled as a categorical variable. For example, fentanyl is typically administered as 25 , 50 or 100 micrograms with other doses used rarely. We adjusted estimates in the final multivariable model with an Elixhauser-Walraven score to account for comorbidity, and we scaled the score to avoid negative values. Walraven adapted the Elixhauser comorbidity index into a single score, which enables a more parsimonious adjustment in analysis. ${ }^{13}$ We specified no interactions in the design and therefore none was tested. Goodness of fit of the final model was tested using the Hosmer and Lemeshow test. ${ }^{14}$ We anticipated variation in survival between hospitals, however if intracluster correlation was low (less than 5\%) for hospital survival then we did not use a multilevel model. ${ }^{16}$ Results from logistic regression models are presented as odds ratios in tabular form. To maximize the sample size of this cohort, we included all cases of RSI from the RSI program inception to date.

\section{Ethics}

Alfred Hospital Ethics Committee provided overall ethics approval for this multisite cohort study. Research governance committees from each of the participating hospitals and Ambulance Victoria provided local approval.

\section{Results}

The seven participating hospitals treated 2277 patients that received paramedic RSI for all illnesses and indications from 2008 to 2015, and survival data was available for 1940 (85\%). Of the 1940 complete survival dataset, 1125 (58\%) had at least one hospital-diagnosed NTBP diagnosis (Figure 1). For the 1125 with NTBP, survival data was complete for 1112 (99\%), and no variable predicted missingness in the NTBP cohort. Twenty-two percent of all RSI patients with a NTBP had more than one instance of NTBP concomitantly, for a total number of 1433 NTBP in 1112 patients (Table 1). Common combinations of NTBP included eight percent had a haemorrhagic stroke and hydrocephalus, five percent that had an ischemic and haemorrhagic stroke, two percent of NTBP had a malignant neoplasm and seizures and 1.2\% had a seizure and a haemorrhagic stroke together. Strokes were the most common, with 345 (24\%) instances of haemorrhagic stroke, 151 (11\%) ischemic stroke and 28(2\%) had a stroke that was not classifiable as either haemorrhagic or ischemic (Table 1). The second and third most common NTBP were toxicity/toxic encephalopathy and seizures, with 324 (23\%) and 315 (22\%) respectively. Our results indicate 69\% percent all of NTBP survived to hospital discharge, compared to $65 \%$ for traumatic intracranial injury. There was large variability in survival for the various NTBP, with haemorrhagic stroke the lowest at $31 \%$ and toxicity 
or toxic encephalopathy the highest survival to discharge at 98\% (Table 1). Haemorrhagic stroke had 93\% lesser odds of survival to hospital discharge, compared to other NTBP; OR = 0.07 (95\% CI 0.05-0.09) and toxicity and toxic encephalopathy had almost 34 times the odds of survival; OR = 33.5 (95\% CI 15.6-71.7) (Table 1).

Forty-three (4\%) of all NTBP died in the emergency department. Furthermore, 49 (4\%) of all NTBP admitted to hospital had an episode of cardiac arrest of which $62 \%$ survived to discharge. Table two presents univariable logistic regression results for demographic, clinical interventions and observations. Multivariable logistic regression for strokes and seizures indicates that age is a predictor of survival to discharge, with decreased survival with increasing age (Table 3). Elixhauser-Walraven comorbidity score was associated with decrease in odds of survival for each additional point in a non-linear function across all multivariable analysis. For the 1940 that received RSI for all indications (trauma and medical) and for whom complete survival data were available, the prevalence of traumatic intracranial injuries was 152 (8\%). The overall RSI intubation success proportion in this NTBP cohort is $98.3 \%$ with no evidence of a significant change in success over the eight year study period, $\chi^{2}(\mathrm{DF}=7)=3.9, \mathrm{p}=0.79$. Of the $468 \mathrm{RSI}$ patients that had at least one kind of hospital-diagnosed stroke, paramedics were able to correctly classify these as having had a stroke in 299 cases (64\%), and classified most of the rest of strokes (31\%) as nonspecific or undiagnosed unconsciousness. After adjustment in the multivariable model, survival did not vary between hospitals and the intraclass correlation coefficient for the correlation of survival within hospitals was 0.002. Consequently, we did not adjust for hospital survival clustering.

\section{Limitations}

The data collected for all RSI (NTBP and all other pathologies) from the seven participating hospitals had 15\% missing survival outcomes, but only one percent of the NTBP had missing survival results. It is clear that data collection for NTBP was more complete than for other illnesses. It is possible that the one percent with missing survival outcomes was systematically different from this cohort causing possible bias, despite our analysis showing that no variable predicts missingness in NTBP. As such, we believe our results are robust and relatively free of non-response bias. We did not describe the 34\% that received RSI for other indications (not NTBP) as it was unfeasible given the large number of ICD10-AM that encodes these other indications. The purpose of this study is to enumerate NTBP only. There is a lack of a consistent definition of NTBP across the published research. ${ }^{10}$ Therefore, the NTBP prevalence might differ somewhat if another definition is used. Even so, we believe our ICD10-AM based definition to be reasonable and it is in accordance with the literature. Survival to discharge of NTBP will depend on the prevalence of various illnesses that comprise NTBP. For example, if a region has more strokes than reported in this study, the survival might be less than the proportion reported here and we caution against extrapolating our results to other regions which might have a different composition of NTBP. 
We only adjusted for comorbidities, but not for the illness severity with a designed- for- purpose score, as illness severity indices were not available for most NTBP. Nonetheless, we have accounted for illness severity with the Glasgow Coma Scale as it is similarly predictive of in-hospital mortality in strokes as NIHSS, ${ }^{17}$ FOUR, ${ }^{18}$ and APACHE II. ${ }^{19}$ Inaccurate coding of ICD10-AM might have caused bias in the period prevalence of NTBP in this cohort. We did not construct separate models for all eight of the NTBP due to sample size limitations for some. We also accounted for comorbidities in our multivariable model with the Elixhauser-Walraven score, to lessen any imbalances in comorbidities across groups. It is important to ensure that comparison groups are similarly sick, as maldistributions of prognosis can seriously bias

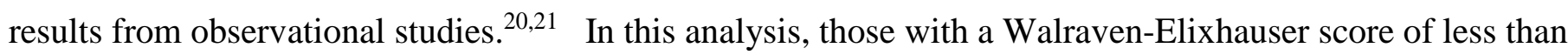
10 had 100\% survival to discharge and this explains the very low survival odds of the higher scores as they are relative to these low scores with perfect survival. In addition, a slight rise and subsequent drop in survival is apparent for middle-range Walraven-Elixhauser scores. We believe that this rise is likely to coding bias, where comorbidities are under-recorded in the acutely ill (such as NTBP), compared to illness that are less acute. ${ }^{22}$ It is likely that an increased capture of ICD10-AM codes the longer a patient stays in hospital, which leads to an association between higher scores and increased survival. An additional analysis shows a 0.34 (95\% CI 0.25 to 0.44 ) point rise for each extra day a patient spends in ICU, suggesting coding bias. All of the NTBP in this study has the potential to cause acute illness, and we believe it is likely that the NTBP recorded for each admission was related to the decision to use RSI but cannot be guaranteed, since it is not always possible to know which NTBP caused RSI, especially in those with multiple concomitant NTBP.

\section{Discussion}

Our results revealed that $58 \%$ of paramedic RSI was on patients with a hospital-diagnosed NTBP, compared to $8 \%$ of all RSI patients with a traumatic intracranial injury. It is evident that NTBP is much more common than traumatic brain injuries among those that receive paramedic RSI in Victoria, Australia. Our results showed a higher prevalence compared to the Bernard study, as our results were derived from inhospital diagnosis, compared to Bernard, which based their estimates on paramedic diagnosis of NTBP. ${ }^{6}$ Survival to hospital discharge for NTBP was four percent higher than those diagnosed with a traumatic intracranial injury (69\% versus 65\%), although there is a large variation in survival amongst the NTBP. Strokes were the most common NTBP, and had poor survival, which is consistent with other stroke studies. ${ }^{23,24}$ Other common NTBP were seizures and toxicity/toxic encephalopathies (alcohol, drug medication or other chemical overdoses and exposures) which had high survival. Furthermore, and keeping in mind that this study was not powered for this purpose, our results showed no evidence of a beneficial or harmful effect of any paramedic administered medications or clinical interventions after adjustment for other covariates. Additionally, no prehospital time interval predicted survival in the group of NTBP or in any subgroup analysis, which is surprising considering that timeliness to treatment is important, especially in strokes. ${ }^{25}$ 
Since this NTBP cohort consists mainly of a subset of stroke patients with very high mortality, and toxicity and seizures with very low mortality, it could be that the prognostic risk in this cohort is powerful enough to negate any impact of rapid paramedic transport. Factors that did predict survival include Glasgow Coma Scale (GCS), duration of mechanical ventilation, age, ICU length of stay and comorbidities.

The results from this study showed that NTBP are seven times more prevalent than traumatic intracranial injuries in patients that receive RSI in Victoria, Australia. Even so, there is no high quality evidence to justify RSI in NTBP. A secondary outcome of the Bernard et al randomized controlled trial showed that RSI by paramedics in head trauma increases the rate of favourable neurologic outcome at 6 months compared with intubation in the hospital. ${ }^{1}$ However, it is not clear that this evidence can be generalized to NTBP. Hypoxia, hypo/hypercapnia ${ }^{26}$, hyperventilation ${ }^{27}$, hypotension ${ }^{28}$, hypertension following laryngoscopy ${ }^{29}$ and aspiration ${ }^{30}$ are potential mechanisms of increased mortality in RSI following traumatic intracranial brain injury. Nevertheless, it is possible that the mechanisms through which RSI might influence mortality in traumatic brain injuries will not be the same as in NTBP. Laryngoscopy raises intracranial pressure (ICP) in head trauma, which could worsen an already elevated ICP. ${ }^{29}$ It is not clear if laryngoscopy is similarly problematic in NTBP such as seizures and toxidromes that are not usually characterised by pronounced rises in ICP. Moreover, it is known that mechanical ventilation increases intrathoracic pressures, which in turn decreases cardiac output. ${ }^{31}$ Moreover, since myocardial dysfunction is commonplace in subarachnoid haemorrhage, ${ }^{32}$ and given that positive pressure ventilation can decrease cardiac output, it follows that ventilation after RSI could decrease cardiac output in SAH. If RSI can cause a decrease in cardiac output in SAH, perhaps it could do so for other types of stroke and NTBP. On the other hand, a recent prospective study found no association between traumatic brain injury and myocardial dysfunction, in contrast to $\mathrm{SAH} .{ }^{32}$ It makes sense that positive pressure ventilation after RSI could affect mortality differently when comparing head trauma and NTBP. These two examples suggest some mechanisms though which RSI can have different mortality and morbidity when comparing traumatic brain injury to NTBP. Given the evidence of RSI in head trauma might not apply to NTBP, and considering our results show that NTBP is much more prevalent than TBI, it is possible that RSI is without an evidence basis in many instances.

This data enabled the analysis of four subgroups: ischemic and haemorrhagic strokes, seizures and toxicity/toxic encephalopathy. Remarkably, concomitant seizures in those patient with haemorrhagic stroke was associated with increased survival, despite seizures being a predictor of mortality, ${ }^{33}$ but others found increased survival similar to our results. ${ }^{34}$ Concomitant ischemic stroke and haemorrhagic stroke showed a two-and-half times increased odds of survival, compared to haemorrhagic stokes only, and this finding remains unexplained. We speculate that in this group of RSI patients, which have a high stoke mortality, this finding could be an artefact of illness severity. 


\section{Conclusions}

This analysis shows that non-traumatic brain pathologies are seven times more prevalent than traumatic brain injuries in patients that receive out-of-hospital RSI in Victoria, Australia. Since the mechanisms through which RSI impact mortality might differ between traumatic brain injuries and NTBP, and given that NTBP is ubiquitous, it follows that the use of RSI in NTBP could be unsupported. As such, there is a requirement for high quality observational research or a controlled trial that compares outcomes for RSI to no RSI in NTBP. 


\section{References}

1. Bernard SA, Nguyen V, Cameron P, Masci K, Fitzgerald M, Cooper DJ, Walker T, Std BP, Myles P, Murray L, David, Taylor, Smith K, Patrick I, Edington J, Bacon A, Rosenfeld JV, Judson R. Prehospital rapid sequence intubation improves functional outcome for patients with severe traumatic brain injury: a randomized controlled trial. Ann Surg 2010; 252(6): 959-65.

2. Lossius HM, Roislien J, Lockey DJ. Patient safety in pre-hospital emergency tracheal intubation: a comprehensive meta-analysis of the intubation success rates of EMS providers. Crit Care 2012; 16(1): R24.

3. Gunning M, Perkins Z, Crilly J, von Rahden R. Paramedic rapid sequence induction (RSI) in a South African emergency medical service: a retrospective observational study. South African medical journal = Suid-Afrikaanse tydskrif vir geneeskunde 2013; 103(9): 632-7.

4. Wang HE, Mann NC, Mears G, Jacobson K, Yealy DM. Out-of-hospital airway management in the United States. Resuscitation 2011; 82(4): 378-85.

5. Davis DP, Hoyt DB, Ochs M, Fortlage D, Holbrook T, Marshall LK, Rosen P. The effect of paramedic rapid sequence intubation on outcome in patients with severe traumatic brain injury. $J$ Trauma 2003; 54(3): 444-53.

6. Bernard SA, Smith K, Porter R, Jones C, Gailey A, Cresswell B, Cudini D, Hill S, Moore B, St Clair T. Paramedic rapid sequence intubation in patients with non-traumatic coma. Emerg Med $\mathrm{J}$ 2015; 32(1): 60-4.

7. Chevignard M, Toure H, Brugel DG, Poirier J, Laurent-Vannier A. A comprehensive model of care for rehabilitation of children with acquired brain injuries. Child: care, health and development 2010; 36(1): 31-43.

8. Khuu W, Chan V, Colantonio A. A systematic review protocol for measuring comorbidity in inpatient rehabilitation for non-traumatic brain injury. Systematic reviews 2015; 4: 14.

9. Chan V, Zagorski B, Parsons D, Colantonio A. Older adults with acquired brain injury: a population based study. BMC Geriatr 2013; 13: 97.

10. Chan V, Pole JD, Keightley M, Mann RE, Colantonio A. Children and youth with non-traumatic brain injury: a population based perspective. BMC neurology 2016; 16: 110.

11. Victoria A. Clinical Practice Guidelines for Ambulance and MICA paramedics. Version 1.1 ed. Doncaster, Victoria; 2016. p. 42 to 7.

12. Young GB. Coma. Annals of the New York Academy of Sciences 2009; 1157: 32-47.

13. van Walraven C, Austin PC, Jennings A, Quan H, Forster AJ. A modification of the Elixhauser comorbidity measures into a point system for hospital death using administrative data. Medical care 2009; 47(6): 626-33.

14. Hosmer DW, Lemeshow S, Sturdivant RX. Applied logistic regression. Wiley series in probability and statistics. 3rd ed. Hoboken, New Jersey: John Wiley \& Sons,; 2013. p. 1 online resource ( v.) ill.

15. Royston $\mathrm{P}$, Sauerbrei W. Multivariable model-building : a pragmatic approach to regression analysis based on fractional polynomials for modelling continuous variables. Chichester, England ; Hoboken, NJ: John Wiley; 2008.

16. Lee V. Using Hierarchical Linear Modeling to Study Social Contexts: The Case of School Effects. Educational Psychologist 2000; 35(2): 125-41.

17. Mansour OY, Megahed MM, Abd Elghany EHS. Acute ischemic stroke prognostication, comparison between Glasgow Coma Score, NIHS Scale and Full Outline of UnResponsiveness Score in intensive care unit. Alexandria Journal of Medicine 2015; 51(3): 247-53.

18. Wijdicks EF, Kramer AA, Rohs T, Jr., Hanna S, Sadaka F, O'Brien J, Bible S, Dickess SM, Foss M. Comparison of the Full Outline of UnResponsiveness score and the Glasgow Coma Scale in predicting mortality in critically ill patients*. Crit Care Med 2015; 43(2): 439-44.

19. Grmec S, Gasparovic V. Comparison of APACHE II, MEES and Glasgow Coma Scale in patients with nontraumatic coma for prediction of mortality. Acute Physiology and Chronic Health Evaluation. Mainz Emergency Evaluation System. Crit Care 2001; 5(1): 19-23. 
20. Fouche PF, Jennings PA. Physician presence at out-of-hospital cardiac arrest is not necessarily the cause of improved survival. Scand J Trauma Resusc Emerg Med 2016; 24(1): 88. 21. Fouche PF, Carlson JN, Ghosh A, Zverinova KM, Doi SA, Rittenberger JC. Frequency of adjustment with comorbidity and illness severity scores and indices in cardiac arrest research. Resuscitation 2017; 110: 56-73.

22. Sharabiani MT, Aylin P, Bottle A. Systematic review of comorbidity indices for administrative data. Medical care 2012; 50(12): 1109-18.

23. Bushnell CD, Phillips-Bute BG, Laskowitz DT, Lynch JR, Chilukuri V, Borel CO. Survival and outcome after endotracheal intubation for acute stroke. Neurology 1999; 52(7): 1374-81.

24. Elmer J, Hou P, Wilcox SR, Chang Y, Schreiber H, Okechukwu I, Pontes-Neto O, Bajwa E, Hess DR, Avery L, Duran-Mendicuti MA, Camargo CA, Jr., Greenberg SM, Rosand J, Pallin DJ, Goldstein JN. Acute respiratory distress syndrome after spontaneous intracerebral hemorrhage*. Crit Care Med 2013; 41(8): 1992-2001.

25. Saver JL. Time is brain--quantified. Stroke 2006; 37(1): 263-6.

26. Holmes J, Peng J, Bair A. Abnormal end-tidal carbon dioxide levels on emergency department arrival in adult and pediatric intubated patients. Prehosp Emerg Care 2012; 16(2): 210-6. 27. Gaither JB, Spaite DW, Bobrow BJ, Denninghoff KR, Stolz U, Beskind DL, Meislin HW. Balancing the potential risks and benefits of out-of-hospital intubation in traumatic brain injury: the intubation/hyperventilation effect. Ann Emerg Med 2012; 60(6): 732-6.

28. Newton A, Ratchford A, Khan I. Incidence of adverse events during prehospital rapid sequence intubation: a review of one year on the London Helicopter Emergency Medical Service. $J$ Trauma 2008; 64(2): 487-92.

29. Perkins ZB, Gunning M, Crilly J, Lockey D, O'Brien B. The haemodynamic response to prehospital RSI in injured patients. Injury 2013; 44(5): 618-23.

30. Vadeboncoeur TF, Davis DP, Ochs M, Poste JC, Hoyt DB, Vilke GM. The ability of paramedics to predict aspiration in patients undergoing prehospital rapid sequence intubation. J Emerg Med 2006; 30(2): 131-6.

31. Soni N, Williams P. Positive pressure ventilation: what is the real cost? Br J Anaesth 2008; 101(4): 446-57.

32. Serri K, El Rayes M, Giraldeau G, Williamson D, Bernard F. Traumatic brain injury is not associated with significant myocardial dysfunction: an observational pilot study. Scand J Trauma Resusc Emerg Med 2016; 24(1): 31.

33. Shinton RA, Gill JS, Melnick SC, Gupta AK, Beevers DG. The frequency, characteristics and prognosis of epileptic seizures at the onset of stroke. J Neurol Neurosurg Psychiatry 1988; 51(2): 2736.

34. Reith J, Jorgensen HS, Nakayama H, Raaschou HO, Olsen TS. Seizures in acute stroke: predictors and prognostic significance. The Copenhagen Stroke Study. Stroke 1997; 28(8): 1585-9. 
Excluded: 152 (8\%) with traumatic intracranial injury and 663 (34\%) with other pathologies that is not NTBP
Seven participating hospitals treated 2277 paramedic RSI for all illness types (trauma and medical) in Melbourne, Australia for 2008 to 2015

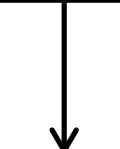

Survival outcomes data for 1940 ( $85 \%$ of total treated by participating sites)

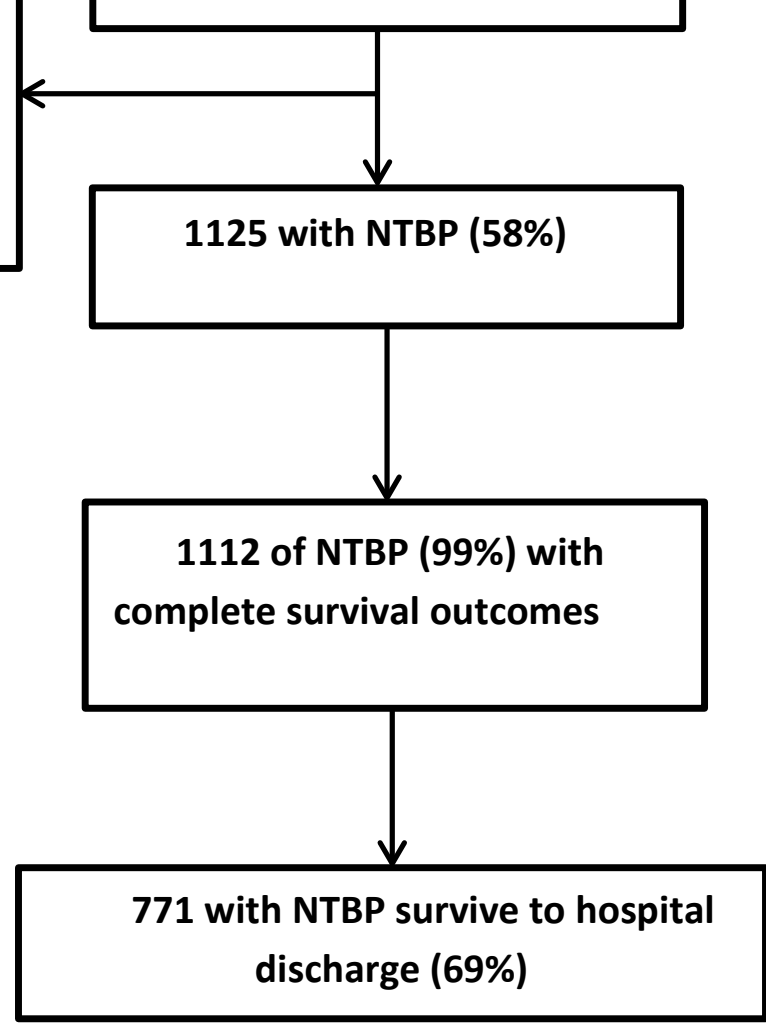

337 (15\%) survival outcome data not received (\% not received from each hospital):

Hospital 1 - 19\%

Hospital $2-38 \%$

Hospital $3-10 \%$

Hospital 4-14\%

Hospital 5 - 9\%

Hospital 6-7\%

Hospital 7 - 3\% 
Table 1 Univariable logistic regression of NTBP that received paramedic RSI, predictors of survival to hospital discharge*

\begin{tabular}{|l|l|l|l|l|l|}
\hline Type of NTBP & NTBP =1433 $\checkmark$ & Survived = 771 & Died = 341 & $\begin{array}{l}\text { Unadjusted OR } \\
\text { (95\% CI) }\end{array}$ & P-value \\
\hline Anoxic brain injury & $44(3.1)$ & $25(56.8)$ & $19(43.2)$ & $0.57(0.30-1.05)$ & 0.08 \\
\hline Encephalitis & $29(2.0)$ & $26(89.7)$ & $3(10.3)$ & $3.47(1.03-11.7)$ & 0.02 \\
\hline $\begin{array}{l}\text { Encephalopathy, other } \\
\text { types }\end{array}$ & $43(3.0)$ & $17(39.5)$ & $26(60.5)$ & $0.20(0.11-0.41)$ & $<0.001$ \\
\hline Haemorrhagic stroke & $345(24.1)$ & $106(30.7)$ & $239(69.3)$ & $0.07(0.05-0.09)$ & $<0.001$ \\
\hline Hydrocephalus & $94(6.6)$ & $38(40.4)$ & $56(59.6)$ & $0.26(0.17-0.40)$ & $<0.001$ \\
\hline $\begin{array}{l}\text { Diabetic metabolic } \\
\text { encephalopathy }\end{array}$ & $26(1.8)$ & $21(80.8)$ & $5(19.2)$ & $1.89(0.70-5.05)$ & 0.18 \\
\hline Ischemic stroke & $151(10.5)$ & $78(51.7)$ & $73(48.3)$ & $0.41(0.29-0.58)$ & $<0.001$ \\
\hline $\begin{array}{l}\text { Malignant brain } \\
\text { neoplasm }\end{array}$ & $26(1.8)$ & $24(92.3)$ & $2(7.7)$ & $5.46(1.28-23.2)$ & 0.003 \\
\hline $\begin{array}{l}\text { Non- } \\
\text { haemorrhagic/ischemic } \\
\text { stroke }\end{array}$ & $28(2.0)$ & $12(42.9)$ & $16(57.1)$ & $0.32(0.15-0.69)$ & 0.003 \\
\hline Seizures & & & & & \\
\hline $\begin{array}{l}\text { Toxicity and toxic } \\
\text { encephalopathy }\end{array}$ & $324(22.6)$ & $317(97.8)$ & $7(2.2)$ & $33.5(15.6-71.7)$ & $<0.001$ \\
\hline Meningitis & $8(0.5)$ & $6(75.0)$ & $2(25.0)$ & $1.11(0.21-5.74)$ & 0.90 \\
\hline
\end{tabular}

*All non-missing data entries are expressed as percentages (in brackets); $\diamond 1112$ RSI patients had 1433 instances of NTBP 
Table 2 Univariable logistic regression of demographic, clinical interventions and observations in NTBP that received paramedic RSI, predictors of survival to hospital discharge $\diamond$ 


\begin{tabular}{|c|c|c|c|c|}
\hline Demographic factor & Survived (\%) & Died (\%) & $\begin{array}{l}\text { Unadjusted OR } \\
(95 \% \mathrm{CI})\end{array}$ & P-value \\
\hline Age (years)* & $47.1(18.6)$ & $67.6(15.4)$ & $0.94(0.93-0.95)$ & $<0.001$ \\
\hline Sex & & & & 0.10 \\
\hline Male & $439(71.4)$ & $176(28.6)$ & 1.0 (ref) & \\
\hline Female & $329(66.7)$ & $164(33.2)$ & $0.80(0.62-1.04)$ & \\
\hline Indeterminate & $1(100)$ & $0(0)$ & N/A & \\
\hline Hospital & & & & $<0.001$ \\
\hline 1 & $82(68.3)$ & 38 (31.7) & 1.0 (ref) & \\
\hline 2 & $38(62.3)$ & $23(37.7)$ & $0.77(0.40-1.45)$ & \\
\hline 3 & $87(85.3)$ & $15(14.7)$ & $2.69(1.37-5.24)$ & \\
\hline 4 & $158(81.4)$ & $36(18.7)$ & $2.03(1.20-3.44)$ & \\
\hline 5 & $196(63.1)$ & 115 (36.9) & $0.79(0.50-1.24)$ & \\
\hline 6 & $168(61.8)$ & $104(38.2)$ & $0.75(0.48-1.18)$ & \\
\hline 7 & $40(80)$ & $10(20)$ & $1.85(0.83-4.09)$ & \\
\hline \multicolumn{5}{|l|}{ Prehospital Clinical Interventions } \\
\hline Airway suctioning & $195(72.4)$ & $74(27.5)$ & $1.22(0.90-1.65)$ & 0.19 \\
\hline Crystalloid fluids (per $1000 \mathrm{ml}$ )* & $1.65(0.89)$ & $1.38(0.75)$ & $1.31(1.14-1.52)$ & $<0.001$ \\
\hline Gastric tube & $594(70.1)$ & $253(29.8)$ & $1.17(0.87-1.57)$ & 0.31 \\
\hline Endotracheal intubation success & $751(69.2)$ & $334(30.7)$ & $0.59(0.20-1.82)$ & 0.34 \\
\hline Fentanyl category $(\mu \mathrm{g})$ & & & & $<0.001$ \\
\hline$\leq 49$ & $95(83.3)$ & $19(16.7)$ & 1.0 (ref) & \\
\hline 50 to 99 & $360(60.0)$ & 237 (39.7) & $0.30(0.18-0.51)$ & \\
\hline$\geq 100$ & $314(78.7)$ & $85(21.3)$ & $0.74(0.43-1.28)$ & \\
\hline $\begin{array}{l}\text { Maximum midazolam/morphine } \\
\text { infusion rate }(\mathrm{mg} / \mathrm{h})^{* *}\end{array}$ & $5(5,7.5)$ & $5(5,5)$ & $1.06(1.03-1.10)$ & $<0.001$ \\
\hline Metoclopramide total (mg)** & $10(10,10)$ & $10(10,10)$ & $0.97(0.92-1.03)$ & 0.37 \\
\hline Oropharyngeal airway & $394(68.5)$ & $181(31.4)$ & $0.92(0.71-1.19)$ & 0.54 \\
\hline Pancuronium category (mg) & & & & $<0.001$ \\
\hline 0 & $340(81.1)$ & 79 (18.9) & 1.0 (ref) & \\
\hline 4 to 16 & $330(61.0)$ & $211(39.0)$ & $0.37(0.27-0.49)$ & \\
\hline$\geq 16$ & $99(66.0)$ & $51(34.0)$ & $0.45(0.29-.68)$ & \\
\hline Total midazolam bolus (mg)** & $10(6,15)$ & $6.5(4.5,10)$ & $1.09(1.06-1.11)$ & $<0.001$ \\
\hline $\begin{array}{l}\text { Total midazolam/morphine infusion } \\
\text { bolus (mg)** }\end{array}$ & $5(2.5,10)$ & $2.5(2.5,7.5)$ & $1.04(1.01-1.07)$ & $<0.001$ \\
\hline Suxamethonium category (mg) & & & & 0.18 \\
\hline$\leq 99$ & $44(67.7)$ & $21(32.3)$ & 1.0 (ref) & \\
\hline $100-124$ & $156(64.7)$ & 85 (35.3) & $0.88(0.49-1.56)$ & \\
\hline $125-149$ & $341(72.5)$ & $129(27.5)$ & $1.26(0.72-2.20)$ & \\
\hline 150 & $228(68.5)$ & $105(31.5)$ & $1.04(0.59-1.83)$ & \\
\hline \multicolumn{5}{|l|}{ Observations } \\
\hline Final ETCO ${ }_{2}(\mathrm{mmHg})^{*}$ & $37.1(7.8)$ & $36.1(6.7)$ & $1.02(0.99-1.04)$ & 0.05 \\
\hline Final Glasgow Coma Scale score** & $3(3,3)$ & $3(3,3)$ & $1.06(0.94-1.20)$ & 0.32 \\
\hline Final pulse rate $(\mathrm{p} / \mathrm{min})^{*}$ & $98.8(20.5)$ & $99.4(22.9)$ & $0.99(0.99-1.01)$ & 0.63 \\
\hline Final respiratory rate $(\mathrm{p} / \mathrm{min})^{*}$ & $15.7(4.7)$ & $15.3(4.7)$ & $1.01(0.99-1.03)$ & 0.13 \\
\hline Final $\mathrm{SpO}_{2}(\%) * *$ & $100(99,100)$ & $100(99,100)$ & $1.04(1.00-1.07)$ & 0.02 \\
\hline Final systolic blood pressure (mmHg)* & $127.3(23.9)$ & $147.2(33.1)$ & $0.97(0.97-0.98)$ & $<0.001$ \\
\hline Elixhauser-Walraven score* & $16.1(7.3)$ & $14.9(6.7)$ & $1.02(1.00-1.04)$ & 0.03 \\
\hline ICU length of stay (24 hours)* & $2.4(1.3,4.9)$ & $2.1(0.9,4.7)$ & $1.08(1.03-1.11)$ & $<0.001$ \\
\hline Initial Glasgow Coma Scale** & $4(3,8)$ & $5(3,7)$ & $0.99(0.96-1.03)$ & 0.81 \\
\hline
\end{tabular}




\begin{tabular}{|c|c|c|c|c|}
\hline Initial pulse rate $(\mathrm{p} / \mathrm{min} .)^{*}$ & $100.9(29.4)$ & $88.8(27.1)$ & $1.01(1.01-1.02)$ & $<0.001$ \\
\hline Initial respiratory rate $(\mathrm{p} / \mathrm{min})^{*}$ & $17.7(7.8)$ & $19.1(7.2)$ & $0.98(0.97-0.99)$ & 0.04 \\
\hline Initial $\mathrm{SpO}_{2}(\%) * *$ & $97(91,99)$ & $97(92,99)$ & $0.99(0.98-1.01)$ & 0.31 \\
\hline $\begin{array}{l}\text { Initial systolic blood pressure } \\
(\mathrm{mmHg})^{*}\end{array}$ & $134.4(39.8)$ & $164.4(45.4)$ & $0.98(0.98-0.99)$ & $<0.001$ \\
\hline Maximum pulse rate $(\mathrm{p} / \mathrm{min})^{*}$ & $117.9(24.6)$ & $115.6(25.8)$ & $1.00(0.99-1.01)$ & 0.16 \\
\hline $\begin{array}{l}\text { Maximum blood sugar level }(\mathrm{mmol} / \mathrm{l}) \\
\begin{array}{l}1.2 \text { to } 4.99 \\
5 \text { to } 9.99 \\
10 \text { to } 14.99 \\
15 \text { to } 19.99 \\
\geq 20\end{array}\end{array}$ & $\begin{array}{l}41(71.9) \\
506(71.1) \\
133(61.9) \\
37(71.2) \\
9(60.0)\end{array}$ & $\begin{array}{l}16(29.1) \\
206(28.9) \\
82(38.1) \\
15(28.9) \\
6(40.0)\end{array}$ & $\begin{array}{l}1.04(0.57-1.90) \\
1.0 \text { (ref) } \\
0.66(0.47-0.91) \\
1.01(0.54-1.86) \\
0.61(0.21-1.74)\end{array}$ & 0.12 \\
\hline Maximum ETCO $2(\mathrm{mmHg})^{*}$ & $46.1(13.0)$ & $43.32(11.3)$ & $1.02(1.00-1.03)$ & $<0.001$ \\
\hline Maximum Glasgow Coma Scale** & $6(3,8)$ & $6(4,8)$ & $1.03(0.99-1.07)$ & 0.12 \\
\hline Maximum respiratory rate $(\mathrm{p} / \mathrm{min})^{*}$ & $21.2(7.8)$ & $21.4(6.9)$ & $1.00(0.99-1.02)$ & 0.77 \\
\hline Maximum SpO2 (\%) * & $99.4(1.7)$ & $99.3(3.1)$ & $1.03(0.97-1.09)$ & 0.30 \\
\hline $\begin{array}{l}\text { Maximum systolic blood pressure } \\
\text { (mmHg)* }\end{array}$ & $160.4(35.3)$ & $191.2(40.1)$ & $0.98(0.97-0.98)$ & $<0.001$ \\
\hline Mechanical ventilation (days)** & $0.92(0.5,2.7)$ & $1.7(0.75,3.8)$ & $1.01(0.97-1.05)$ & 0.57 \\
\hline $\begin{array}{l}\text { Minimum blood sugar level }(\mathrm{mmol} / \mathrm{l}) \\
\leq 1.2 \\
1.2 \text { to } 4.99 \\
5 \text { to } 9.99 \\
10 \text { to } 14.99 \\
15 \text { to } 19.99 \\
\geq 20\end{array}$ & $\begin{array}{l}8(57.4) \\
59(74.7) \\
499(70.5) \\
121(62.4) \\
31(70.4) \\
8(61.5)\end{array}$ & $\begin{array}{l}6(42.9) \\
20(25.3) \\
209(29.5) \\
73(37.6) \\
13(29.6) \\
5(38.5)\end{array}$ & $\begin{array}{l}1.0 \text { (ref) } \\
2.21(0.68-7.16) \\
1.79(0.61-5.22) \\
1.24(0.41-3.72) \\
1.79(0.52-6.12) \\
1.20(0.26-5.59)\end{array}$ & 0.22 \\
\hline Minimum $\mathrm{ETCO}_{2}(\mathrm{mmHg})^{*}$ & $33.9(8.3)$ & $32.6(6.2)$ & $1.02(1.00-1.04)$ & 0.02 \\
\hline Minimum Glasgow Coma Scale** & $3(3,3)$ & $3(3,3)$ & $1.05(0.91-1.21)$ & 0.47 \\
\hline Minimum pulse rate (p/min)* & $83.9(23.4)$ & $76.5(23.8)$ & $1.01(1.00-1.02)$ & $<0.001$ \\
\hline Minimum respiratory rate $(\mathrm{p} / \mathrm{min})^{* *}$ & $12(10,16)$ & $12(12,16)$ & $0.99(0.97-1.01)$ & 0.20 \\
\hline Minimum $\mathrm{SpO}_{2}(\%) *$ & $91.4(11.4)$ & $91.3(12.7)$ & $0.99(0.99-1.01)$ & 0.94 \\
\hline $\begin{array}{l}\text { Minimum systolic blood pressure } \\
(\mathrm{mmHg})^{*}\end{array}$ & $107.3(26.9)$ & $126.9(34.3)$ & $0.98(0.97-0.98)$ & $<0.001$ \\
\hline Cardiac arrest & $30(61.2)$ & $19(38.8)$ & $0.68(0.38-1.24)$ & 0.22 \\
\hline Response time* & $38.8(29.2)$ & $39.5(30)$ & $0.99(0.99-1.00)$ & 0.71 \\
\hline Scene time* & $77.2(24.9)$ & $75.9(20.0)$ & $1.00(0.99-1.00)$ & 0.39 \\
\hline Transport time* & $39.0(23.4)$ & $37.0(20.3)$ & $1.00(0.99-1.00)$ & 0.20 \\
\hline Prehospital time (total, minutes)* & $154.9(43.6)$ & $152.5(37.9)$ & $1.00(0.99-1.00)$ & 0.28 \\
\hline
\end{tabular}

Table 3 Multivariable logistic regression of prehospital predictors of survival to hospital discharge for RSI strokes, seizures and toxic encephalopathy 
HAEMORRHAGIC STROKE (N=345)

\begin{tabular}{|c|c|c|}
\hline Age (years) & $0.96(0.94-0.98)$ & 0.001 \\
\hline $\begin{array}{l}\text { Elixhauser-Walraven score } \dagger \\
\qquad \begin{array}{l}5 \\
10 \\
20 \\
30 \\
40\end{array}\end{array}$ & $\begin{array}{l}1.00 \text { (ref) } \\
0.0008(0.001-0.06) \\
0.002(0.001-0.13) \\
0.008(0.001-0.53) \\
0.007(0.001-3.60)\end{array}$ & $<0.001$ \\
\hline Concomitant ischemic stroke & $2.57(1.12-5.90)$ & 0.03 \\
\hline Mechanical ventilation (days) & $1.15(1.06-1.25)$ & $<0.001$ \\
\hline Concomitant seizures & $44.6(5.00-394.7)$ & 0.001 \\
\hline Maximum systolic blood pressure (mmHg) & $0.99(0.98-0.99)$ & 0.005 \\
\hline Concomitant other encephalopathy types & $0.02(0.002-0.14)$ & $<0.001$ \\
\hline \multicolumn{3}{|l|}{ ISCHEMIC STROKE (N=151) } \\
\hline Age (years) & $0.96(0.93-0.98)$ & 0.002 \\
\hline $\begin{array}{l}\text { Elixhauser-Walraven score } \dagger \\
5 \\
10 \\
20 \\
30 \\
40\end{array}$ & $\begin{array}{l}1.00 \text { (ref) } \\
0.01(0.001-0.63) \\
0.04(0.001-2.43) \\
0.02(0.001-1.75) \\
0.01(0.001-2.64)\end{array}$ & $<0.001$ \\
\hline ICU stay & $2.48(0.92-6.67)$ & 0.07 \\
\hline Concomitant seizures & $7.39(1.56-34.8)$ & 0.01 \\
\hline Initial GCS & $1.18(1.02-1.36)$ & 0.02 \\
\hline Concomitant other encephalopathy types & $0.02(0.001-0.40)$ & 0.012 \\
\hline \multicolumn{3}{|l|}{ SEIZURES (N=316) } \\
\hline Age (years) & $0.95(0.92-0.99)$ & 0.007 \\
\hline $\begin{array}{l}\text { Mechanical ventilation (days) } \dagger \dagger \\
1 \\
5 \\
10 \\
20\end{array}$ & $\begin{array}{l}1.00 \text { (ref) } \\
0.40(0.19-0.87) \\
0.39(0.18-0.87) \\
0.38(0.17-0.86)\end{array}$ & 0.001 \\
\hline Elixhauser & $0.99(0.91-1.07)$ & 0.85 \\
\hline Concomitant other encephalopathy types & $0.13(0.03-0.60)$ & 0.008 \\
\hline \multicolumn{3}{|c|}{ TOXICITY AND TOXIC ENCEPHALOPATHY (N=324) } \\
\hline $\begin{array}{l}\text { Mechanical ventilation (days) } \dagger \dagger \dagger \\
1 \\
5 \\
10 \\
20\end{array}$ & $\begin{array}{l}1.00 \text { (ref) } \\
0.16(0.02-1.55) \\
0.13(0.01-1.65) \\
0.11(0.007-1.69)\end{array}$ & 0.01 \\
\hline Elixhauser & $0.88(0.78-0.98)$ & 0.02 \\
\hline Concomitant anoxic injury & $0.10(0.02-0.73)$ & 0.02 \\
\hline
\end{tabular}

$(\text { Elixhauser }+1 / 10)^{3}+\beta_{2}(\text { Elixhauser }+1 / 10)^{3} \ln +\beta_{3}(\text { Elixhauser }+1 / 10)^{3} \ln ^{2}$ 
$+\beta_{4}$ (Elixhauser $\left.+1 / 10\right)^{3} \ln ^{3} ; †$ Mechanical ventilation fitted as fractional polynomial terms $\beta_{1}(\text { Mechanical ventilation/10 })^{-2}$

$+\beta_{2}$ (Mechanical ventilation $\left./ 10\right)^{-2} \ln ; \dagger †$ Mechanical ventilation fitted as fractional polynomial terms: $\beta_{1}(\text { Mechanical ventilation }+0.04 / 10)^{-1}$

Variables included in multivariable were only those that were significant at the $5 \%$ level.

Table S1 ICD10 AM codes used to practically define NTBI cases from hospital data

\begin{tabular}{|c|c|}
\hline Type of NTBI & ICD 10 AM codes and description \\
\hline Haemorrhagic stroke & $\begin{array}{l}\text { I60 (subarachnoid haemorrhage) } \\
\text { I61 (intracerebral heammorhage) } \\
\text { P52 (intracranial nontraumatic heammorhage of foetus and } \\
\text { newborn) } \\
\text { I62.9 (intracranial heammorhage (nontraumatic), unspecified) }\end{array}$ \\
\hline Ischemic stroke & $\begin{array}{l}\text { I63 (cerebral infarction) } \\
\text { G45 (transient cerebral ischemic attacks and related syndromes) }\end{array}$ \\
\hline Other types of stroke & I64 (stroke not specified as heammorhage or infarction) \\
\hline $\begin{array}{l}\text { Inflammatory brain } \\
\text { diseases }\end{array}$ & $\begin{array}{l}\text { G00 (bacterial meningitis, not elsewhere classified) } \\
\text { G01 (meningitis in bacterial diseases classified elsewhere) } \\
\text { G02 (meningitis in other infectious and parasitic diseases classified } \\
\text { elsewhere) } \\
\text { G03 (meningitis due to other and unspecified causes) } \\
\text { A20.3 (plague meningitis) } \\
\text { A83 (mosquito born viral encephalitis) } \\
\text { A84 (tick born viral encephalitis) } \\
\text { A85 (other viral encephalitis, not elsewhere classified) } \\
\text { A81 (atypical viral infections of the central nervous system) } \\
\text { A87 (viral meningitis) } \\
\text { B50 (cerebral malaria) } \\
\text { G04 (encephalitis, myelitis and encephalomyelitis) } \\
\text { G05 (encephalitis, myelitis and encephalomyelitis in diseases } \\
\text { classified elsewhere } \\
\text { G06 (intracranial abscess and granuloma) } \\
\text { G07 (intracranial and intra-spinal abscess and granuloma in }\end{array}$ \\
\hline
\end{tabular}




\begin{tabular}{|c|c|}
\hline & $\begin{array}{l}\text { G08 (Intracranial and intra-spinal phlebitis and thrombophlebitis) } \\
\text { B22 (HIV disease resulting in encephalopathy) }\end{array}$ \\
\hline $\begin{array}{l}\text { Anoxic/hypoxic brain } \\
\text { injury }\end{array}$ & $\begin{array}{l}\text { G93.1 (anoxic brain damage) } \\
\text { G97.8 (brain(nontraumatic) hypoxia, resulting from procedure) } \\
\text { P20.9 (brain(nontraumatic) hypoxia, anoxic intrauterine and } \\
\text { resulting from birth) } \\
\text { T88.5 (complications resulting from a procedure anoxic/hypoxic } \\
\text { brain damage) } \\
\text { P91.6 (hypoxic ischemic encephalopathy of newborn) }\end{array}$ \\
\hline Seizures & $\begin{array}{l}\text { G41 (status epilepticus) } \\
\text { G40 (epilepsy) } \\
\text { F445 (dissociative convulsions) } \\
\text { P90 (convulsions of newborn) } \\
\text { R56 (convulsions, not elsewhere classified) }\end{array}$ \\
\hline $\begin{array}{l}\text { Toxicity and toxic } \\
\text { encephalopathy }\end{array}$ & $\begin{array}{l}\text { G92 (toxic encephalopathy) } \\
\text { T51 -T65 (toxic effect of alcohol, organic solvents, etc.) } \\
\text { T36 -T51 (poisoning by drugs, medicaments and biological } \\
\text { substances) } \\
\text { X40 - X49 (accidental poisoning by and exposure to noxious } \\
\text { substances) } \\
\text { X60 - X69 (intentional self-poisoning) }\end{array}$ \\
\hline Neoplasms of brain & $\begin{array}{l}\text { C70 (malignant neoplasms of meninges) } \\
\text { C71 (malignant neoplasm of the brain) } \\
\text { C793 (secondary malignant neoplasm of the brain and cerebral } \\
\text { meninges) }\end{array}$ \\
\hline Hydrocephalus & $\begin{array}{l}\text { G91.0(communicating hydrocephalus) } \\
\text { G91.1 (obstructive hydrocephalus) } \\
\text { G91.2 (normal-pressure hydrocephalus) } \\
\text { G94 (hydrocephalus other) } \\
\text { G91.8 (other hydrocephalus) } \\
\text { G91.9 (hydrocephalus, unspecified) }\end{array}$ \\
\hline
\end{tabular}




\begin{tabular}{|c|c|}
\hline $\begin{array}{l}\text { Diabetic metabolic } \\
\text { encephalopathy }\end{array}$ & $\begin{array}{l}\text { E15( nondiabetic hypoglycaemic coma) } \\
\text { E16.1-E61.2 (other hypoglycaemia and hypoglycaemia } \\
\text { unspecified) } \\
\text { E10.0(insulin dependent diabetes mellitus with coma) } \\
\text { E10.4 (insulin dependent diabetes mellitus with neurological } \\
\text { complications) } \\
\text { E11 (non-insulin dependent diabetes mellitus with coma) } \\
\text { E11.4 (non-insulin dependent diabetes mellitus with neurological } \\
\text { complications) } \\
\text { E12 (malnutrition related diabetes mellitus with neurological } \\
\text { complications) } \\
\text { E13 (other specified diabetes mellitus with coma) } \\
\text { E14.0 (unspecified diabetes mellitus with coma) } \\
\text { E14.4 (unspecified diabetes mellitus with coma) }\end{array}$ \\
\hline Other encephalopathies & $\begin{array}{l}\text { B15 (hepatitis A with hepatic coma) } \\
\text { B16 (hepatitis B with hepatic coma (with delta agent)) } \\
\text { B16.2 (hepatitis B with hepatic coma (without delta agent)) } \\
\text { B19 (unspecified viral hepatitis with hepatic coma) } \\
\text { E03.5 (myxoedema coma) } \\
\text { E51.2 (wernickes encephalopathy) } \\
\text { G93.4 (encephalopathy, unspecified and metabolic) } \\
\text { G93.5 (non-traumatic compression of brain) } \\
\text { G93.6 (non-traumatic cerebral oedema) } \\
\text { I67.4 (hypertensive encephalopathy) } \\
\text { T67 (heatstroke) }\end{array}$ \\
\hline
\end{tabular}


Table S2 Multivariable logistic regression of prehospital predictors of survival to hospital discharge for RSI in all NTBP

\begin{tabular}{|c|c|c|}
\hline Factor & Adjusted OR (95\% CI) & P-value \\
\hline Age (years) & $0.95(0.94-0.97)$ & $<0.001$ \\
\hline Anoxic brain injury & $0.19(0.07-0.55)$ & 0.001 \\
\hline Elixhauser-Walraven score $†$ & & $<0.001$ \\
\hline 5 & 1.00 (ref) & \\
\hline 10 & $0.002(0.001-0.09)$ & \\
\hline 20 & $0.01(0.001-0.22)$ & \\
\hline 30 & $0.02(0.001-0.24)$ & \\
\hline 40 & $0.003(0.001-0.11)$ & \\
\hline Final pulse rate (p/min) & $0.99(0.98-0.99)$ & 0.008 \\
\hline Haemorrhagic stroke (yes) & $0.32(0.19-0.54)$ & $<0.001$ \\
\hline ICU stay & $1.68(1.06-2.69)$ & 0.03 \\
\hline Initial pulse rate $(\mathrm{p} / \mathrm{min}.) \dagger \dagger$ & & 0.002 \\
\hline 40 & $0.94(0.90-0.98)$ & \\
\hline 60 & 1.00 (ref) & \\
\hline 70 & $1.05(1.02-1.08)$ & \\
\hline 100 & $1.37(1.12-1.67)$ & \\
\hline 150 & $3.59(1.60-8.07)$ & \\
\hline Maximum blood sugar level (mmol/l) & & 0.04 \\
\hline 1.2 to 4.99 & $0.23(0.09-0.61)$ & \\
\hline 5 to 9.99 & 1.0 (ref) & \\
\hline 10 to 14.99 & $1.16(0.68-1.96)$ & \\
\hline 15 to 19.99 & $1.59(0.61-4.15)$ & \\
\hline$\geq 20$ & $1.23(0.25-5.97)$ & \\
\hline Glasgow Coma Scale $\$$ & $1.11(1.04-1.18)$ & 0.001 \\
\hline Seizures & $15.18(7.53-30.6)$ & $<0.001$ \\
\hline Toxicity and toxic encephalopathy & $25.47(9.78-66.3)$ & $<0.001$ \\
\hline Other encephalopathy types & $0.10(0.03-0.30)$ & $<0.001$ \\
\hline
\end{tabular}

† Elixhauser score fitted as fractional polynomial terms: $\beta_{1}$ (Elixhauser $\left.+1 / 10\right)^{3}+\beta_{2}(\text { Elixhauser }+1 / 10)^{3} \ln$

$+\beta_{3}(\text { Elixhauser }+1 / 10)^{3} \ln ^{2}+\beta_{4}$ (Elixhauser $\left.+1 / 10\right)^{3} \ln ^{3}+\dagger$ Initial pulse rate fitted as a fractional polynomial

term: $\beta_{1}$ (Initial pulse rate $\left.+1 / 10\right)^{3}$. \$ Highest Glasgow Coma scale measured by paramedics on scene. Variables

included in multivariable were only those that were significant at the $5 \%$ level. 